\title{
The representation of semantic similarities between object concepts in the brain: a hypergraph-based model
}

\author{
Kaoutar Skiker $^{1 *}$, Mounir Maouene ${ }^{2}$ \\ From The Twenty Third Annual Computational Neuroscience Meeting: CNS*2014 \\ Québec City, Canada. 26-31 July 2014
}

The understanding of how semantic similarities between object concepts are reflected in the brain is a fundamental issue in cognitive neuroscience $[1,2]$. fMRI studies have provided evidence that similar objects are grouped or clustered together into categories along a number of semantic features including visual, functional, tactile, sound, smell, taste and action features $[3,4]$.

Traditionally, the relation between brain regions have been represented as graphs, where nodes denote brain regions and edges denote functional or structural connections between them[5].Neuroimaging studies have implicated a number of these regions, known as modality-specific areas, as representing specific knowledge of objects[4].These knowledge includes a number of visual ,functional and encyclopedic features. These features are of a particular interest because they allow people to make comparison between objects. Like brain networks, semantic similarities between objects may be represented as graphs; in that case, nodes represent objects and links represent the presence of a common feature. However, it is not possible to retrieve what constitute the meanings of these links.

In this study, we propose to represent semantic similarities between objects with the mathematical model of hypergraph, a generalization of the graph model. The benefits of using hypergraphs for representing object similarities are threefold. First, links between objects, called hyperedges, connect a set of nodes and not just binary nodes as in graphs, such that the complexity of the similarities between objects can be preserved. Second, and unlike in graphs, links in hypergraphs keep their semantic, such that the semantic path between the

\footnotetext{
* Correspondence: skiker.kaoutar85@gmail.com

'LIST Laboratory, FST, Abdelmalek Essaadi's University, Tangier, Morocco

Full list of author information is available at the end of the article
}

similarities can be traced. Third, in a hypergraph, the clusters of objects overlap, because one category can share one or more of its semantic features with one or more categories and, by extension, a group of categories. We build a hypergraph for objects and their features based on the results available in neuroimaging studies including 1)-studies that have addressed the issue of how semantic similarities between object concepts are reflected in the brain [1,2], 2) studies that have examined how object concepts of different categories are organized in the brain $[3,4,6]$, and also 3 )-studies that have investigated the differences and similarities for processing object-related nouns and action-related verbs in the brain [7].

To summarize, hypergraphs provide an important approach for representing similarities between objects in the brain from the semantic perspective and provide a useful structure for representing clusters-based similarity.

\section{Authors' details \\ 'LIST Laboratory, FST, Abdelmalek Essaadi's University, Tangier, Morocco. 2Department of computer science, ENSAT, Abdelmalek Essaadi's University, Tangier, Morocco.}

\section{Published: 21 July 2014}

\section{References}

1. Bruffaerts R, Dupont P, Peeters R, De Deyne $S$, Storms $G$, Vandenberghe R: Similarity of fMRI activity patterns in left perirhinal cortex reflects semantic similarity between words. J Neurosci 2013, 33:18597-18607.

2. Connolly AC, Guntupalli JS, Gors J, Hanke M, Halchenko YO, Wu Y-C, Abdi $\mathrm{H}$, Haxby JV: The representation of biological classes in the human brain. J Neurosci 2012, 32:2608-2618.

3. Huth AG, Nishimoto S, Vu AT, Gallant JL: A continuous semantic space describes the representation of thousands of object and action categories across the human brain. Neuron 2012, 76:1210-1224.

4. Martin A: The representation of object concepts in the brain. Annu Rev Psychol 2007, 58:25-45. 


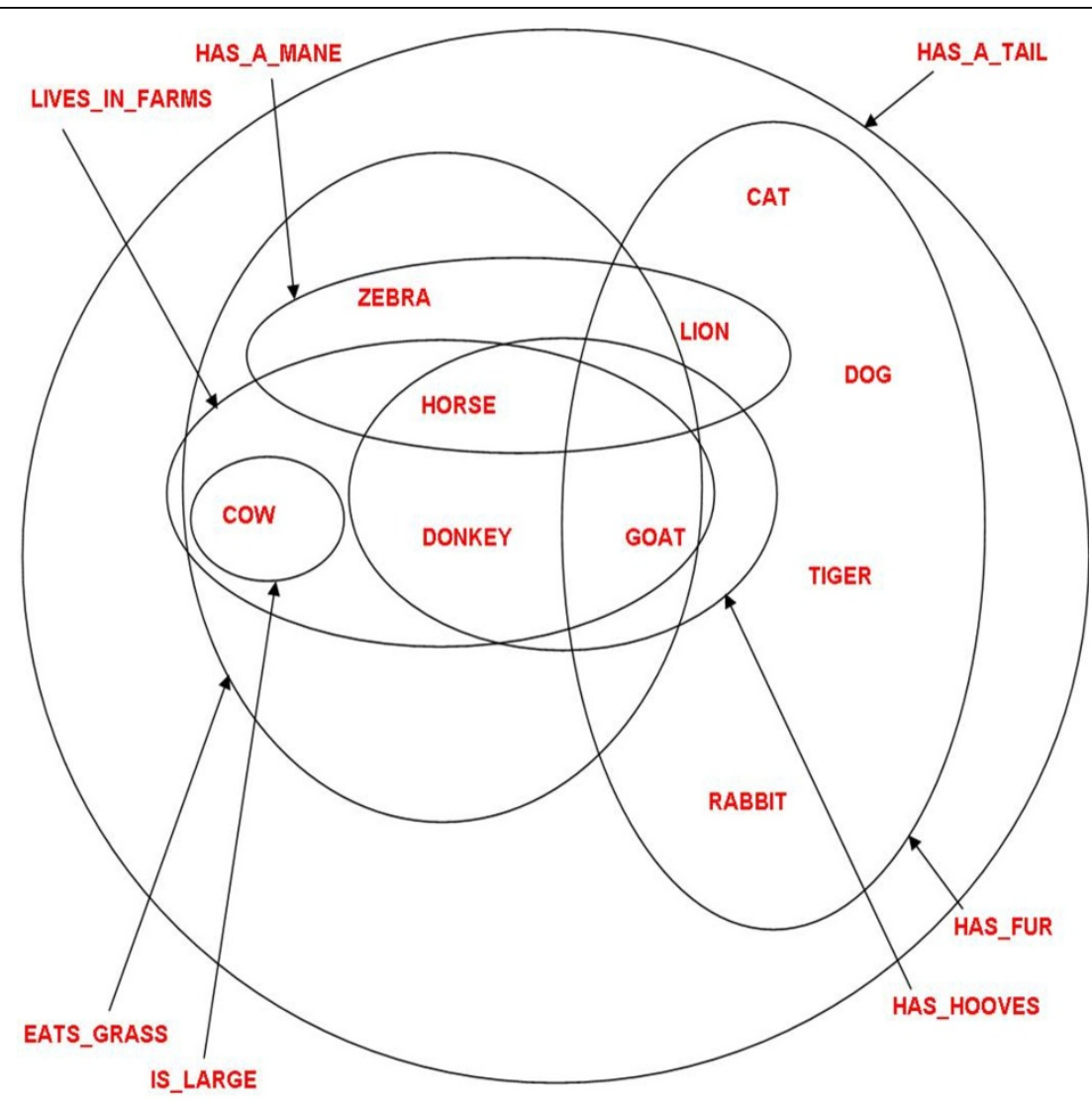

Figure $1 \mathrm{~A}$ hypergraph of the semantics similarities between animals

5. Bullmore E, Sporns O: Complex brain networks: graph theoretical analysis of structural and functional systems. Nat Rev Neurosci 2009, 10:186-198.

6. Tyler LK, Chiu S, Zhuang J, Randall B, Devereux BJ, Wright P, Clarke A, Taylor Kl: Objects and categories: feature statistics and object processing in the ventral stream. J Cogn Neurosci 2013, 25:1723-1735.

7. Vigliocco G, Vinson DP, Druks J, Barber H, Cappa SF: Nouns and verbs in the brain: a review of behavioural, electrophysiological, neuropsychological and imaging studies. Neurosci Biobehav Rev 2011, 35:407-426.

\section{Submit your next manuscript to BioMed Central and take full advantage of:}

- Convenient online submission

- Thorough peer review

- No space constraints or color figure charges

- Immediate publication on acceptance

- Inclusion in PubMed, CAS, Scopus and Google Scholar

- Research which is freely available for redistribution

Submit your manuscript at www.biomedcentral.com/submit 